\section{Repensando a linguagem secular $e$ liberal}

\section{Rethinking the secular and the liberal language}

ASAD, Talal. Secular translations: nation state, modern self, and calculative reason, New York, Columbia University Press, 2018. 222p.

\section{Marcelo Moura Mello \\ https://orcid.org/0000-0002-9460-2824}

Departamento de Antropologia e Etnologia da Universidade Federal da Bahia (UFBA), Salvador Bahia,Brasil.E-mail:mmmello@gmail.com

DOI: $10.1590 / 3510203 / 2020$

O mais recente livro de Talal Asad (1932) resulta de conferências ministradas no âmbito das Ruth Benedict Lectures, promovidas pelo departamento de antropologia da Columbia University desde 2017. Em três ensaios, o autor aborda a ideia de secular, buscando descobrir como sentimentos, conceitos e atitudes articulam discursos no/sobre o secular e o religioso na vida contemporânea. Em sua visão, um entendimento mais acurado sobre o secularismo, um conceito dominante na vida moderna, demanda uma abordagem indireta, princípio articulado desde Formations of the Secular (Asad, 2003). A tarefa à qual Asad se propóe consiste em analisar as variaçóes das teias de conceitos que constituem o secular, conferindo especial atenção, em sua mais recente obra, à maneira pela qual distintas formações do secular são traduzidas em saberes, práticas de poder, discursos, orientaçóes afetivas e sensibilidades. $\mathrm{O}$ secularismo não é então tomado enquanto um princípio abstrato de igualdade e liberdade, já dado e isento de contradiçóes, com o qual estados liberais democráticos se encontrariam naturalmente comprometidos.

Conforme expóe Asad, os três ensaios são interligados pela noção de tradução (p. 3). Isso porque a transmissão de ideias do passado e a herança de práticas incorporadas são, na visão de Asad, centrais para entendimentos mútuos; embora o senso de traduçấo nem sempre seja o mesmo em cada instância de comunicação e ação, pois signos, enquanto objetos de conhecimento, não são o mesmo que signos traduzidos em corpos sensíveis por meio do cultivo de sensibilidades (p. 3-5). Nesse sentido, embora a noção de tradução intersemiótica de Roman Jakobson ofereça elementos interessantes para pensar diferentes modos de tradução (traduções intralingual, interlingual e intersemióticas), o modelo do linguista russo não atentaria suficientemente para o fato das práticas cultivadas do self não serem necessariamente sistemas de signos não-verbais (isto é, portadores de significados). Elas são, para Asad, formas de aprender como viver em dada tradição. Assim, "[a] tradição discursiva não é meramente um processo verbal; é também, e prioritariamente, uma continuidade implícita no hábito, no sentimento e no comportamento que se adquire enquanto membro de um modo de vida compartilhado que é traduzido de um período de tempo a outro" (p. 5). Uma vez que toda tradução de uma língua para outra - ou mesmo no interior de uma mesma língua, como notou Jakobson - é uma transformação, traduçôes não são, puramente, atos cognitivos, mas algo dependente de sensibilidades, que são produto de experiências mutáveis de corpos sensíveis ao longo do tempo (p. 6-7).

No primeiro ensaio, "Igualdade secular e linguagem religiosa", Asad escrutina a visão que postula origens cristãs para a emergência do secularismo moderno; isto é, o primado segundo o qual as ideias seculares representam uma tradução moderna de certos valores da cristandade. De imediato, o autor enfatiza: reivindicar a herança cristã do secularismo tem por efeito a exclusão política de todos aqueles que não podem reivindicar tal herança. No caso da Europa, o princípio de igualdade no interior da comunidade política não é facilmente estendível a muçulmanos nascidos no continente. Assim, a suposiçáo de que o secularismo demande absoluta neutralidade para com seus cidadãos, independentemente de sua fé, é extremamente problemático (p. 14-15; 31-36).

Asad enfrenta esta e outras questões, analisando, primeiramente, as várias interpretações sobre a igualdade no estado secular; um valor, em suas diversas instâncias, fundamental para o secularismo político e para o liberalismo. O direito de todos de acreditar em qualquer religião e, ainda assim, recu- 
sar quem a pratica significa, dentre outras coisas, que, no âmbito do poder estatal, princípios secularistas negam o direito da religião prevalecer. Embora ideologicamente o liberalismo desconfie da intervenção estatal, ele requer que o governo seja forte o suficiente para proteger a liberdade religiosa e controlar paixóes religiosas. A evocação da linguagem liberal para afirmar princípios centrais do secularismo é sustentada por sentimentos e crenças inerentemente ambíguos acerca de noçóes como razoabilidade, igualdade e liberdade. Desse modo, a linguagem do liberalismo, do secularismo, e da religião, é utilizada e contestada na prática. Precisamente por isso, o emprego interconectado de certas categorias pode fazer sentido em determinado modo de vida, mas não em outro (p. 16-25). Isso se dá em um momento histórico no qual a secularização não se limita a transformar, simplesmente, o entendimento sobre a religiāo; ela transforma a ideia de política do estado liberal secular, representando uma mudança fundamental na gramática ${ }^{1} \mathrm{da}$ religião e de seu vocabulário associado (p. 18; 25), bem como no conteúdo e escopo daquilo que é definido como política (p. 31). A igualdade legal não é um parâmetro universal, mas algo reivindicado em disputas (p. 27); uma noção ambígua reconhecida de formas diferentes e contraditórias, capaz, paradoxalmente, de produzir desigualdades (p. 38).

Após analisar diversas conceitualizaçóes sobre a igualdade (expressas pela linguagem dos direitos humanos, pelos mecanismos de conversão de direitos morais em direitos legais, e por discursos de políticas, como a de Margaret Thatcher), Asad dialoga com a proposta teórica pós-secularista de Jürgen Habermas, segundo a qual discursos religiosos poderiam ser convertidos em comprometimentos políticos na esfera pública, de modo a tornar a política liberal mais inclusiva, estendendo-se mesmo a pessoas que professam credos religiosos. Nessa proposta, quando tais pessoas fazem legitimamente uso da linguagem religiosa, em esferas públicas dominadas pela linguagem secular, elas estão exercendo o princípio secular de igualdade - desde que o conteúdo verbalizado seja traduzível em uma linguagem universalmente entendível, acessível inclusive a não crentes. Segundo Asad, tal proposição teórica ainda faz parte da tentativa de busca por modos seculares de expansão do domínio do político (p. 43-44). Para além disso, segundo Asad, a visão de Habermas se assenta em uma série de implícitos. Seus enfoques teóricos são eminentemente discursivos e desconsideram a falta de capacidade de um número expressivo de cidadáos de aprender as convençôes envolvidas em debates públicos críticos. Tal visão parece ignorar o fato de que a insistência no diálogo racional e no respeito mútuo constitui importante tática do poder político. Por fim, ela assume que os problemas a serem discutidos na esfera pública são passíveis de fácil identificação e formulação por indivíduos autônomos, que, não obstante suas diferenças, conceberiam de igual maneira os problemas e suas soluçóes - implícita a essa visão é a concepção de linguagem enquanto um sistema neutro de descrição e argumentação (p. 44-46; 50).

Para Asad, há em Habermas dois entendimentos essenciais sobre "religião": uma linguagem e uma prática herdadas do cristianismo que define o estado secular (religião 1); e uma linguagem e uma prática de crentes liberais que vivem em uma sociedade secular e redefiniram sua religiosidade (religião 2). Nesse esquema, a religião liberal não equivale à religião pré-liberal, visto que ela incorporou premissas do estado e da razão seculares, desenvolvendo novas sensibilidades e atitudes. Não há lugar para religióes pré-liberais incapazes de se ajustar à modernidade no mundo político de Habermas, sentencia Asad. (p. 46; 49). Habermas não enfrentaria suficientemente, portanto, os limites da linguagem política liberal e secular de imaginar e viver outras formas de vida² (p. 51).

O segundo ensaio, "Tradução e o Corpo Sensível", versa sobre questôes relativas à tradução e à (in) traduzibilidade, privilegiando a análise de material textual; em especial, obras e reflexóes de teólogos e intelectuais muçulmanos sobre a doutrina da inimitabilidade do Corão, constituindo razão primordial para a relutância de muitos muçulmanos em traduzi-lo do árabe - o que não preveniu a formação de um vasto corpus interpretativo do Corão em outras línguas. Aprofundando ideias apresentadas na introdução da obra, Asad problematiza, no decorrer do capítulo, não só os entendimentos de filósofos, teólogos, antropólogos e pensadores ocidentais sobre a intraduzibilidade do Corão,; como também as con- 
cepçóes sobre linguagem subjacentes a essas análises. Em paralelo, escrutina os implícitos de conceitos como emoção, experiência, ritual e estética, além de comparar as ideias de tradução do Corão com ideias cristâs e antropológicas. Dois princípios devem ser retidos a esse respeito: em primeiro lugar, a traduzibilidade é sempre algo relativo ao que pode ser traduzido, e a como fazê-lo ; em segundo lugar, a busca pelo ponto de vista nativo é compatível com abordagens instrumentais, que concebem formas de vida nativas como meras informaçóes a serem traduzidas de acordo com propósitos completamente exteriores a elas (p. 8-9).

Abordando a atitude reverencial de fiéis em relação a Deus - gesto que combina sentimento e ato, visibilidade pública e pensamento privado -, Asad destaca que a recitação do Corão no original em árabe, sobretudo em contextos litúrgicos, é um ato de reverência ao Criador, e cujo sentido não é totalmente traduzível em discursos escritos, pois requer o cultivo de certas virtudes e habilidades (p. 57 61; 73-74). Entender o significado de mensagens transmitidas por meio de discursos não tem necessariamente, como pré-condição, separá-las de seus meios de expressão ou abstrair o sentido intelectual de textos. Os significados do Corão não são determinados mecanicamente por critérios lógicos ou léxicos. Sua recitação se articula em meio ao processo de desenvolvimento de sensibilidades em uma forma de vida específica (p. 75-76). Deste modo, a linguagem não é somente o que nós fazemos com ela - como pensa Austin -, mas também o que ela faz "para nós" e "em nós" (p. 64 - grifos de Asad).

Esses pontos são elaborados por meio de uma reflexão crítica às ideias de ritual e ritualização. Em consonância à sua famosa crítica a Clifford Geertz (Asad, 1993), o autor questiona interpretaçóes que privilegiam a decifração de símbolos expressos em rituais, bem como o destaque conferido às suas funçôes sociais, em benefício de uma análise atenta às práticas corporais. Sem qualquer pretensão de oferecer uma nova teoria sobre o ritual, Asad sustenta que o significado do termo reside em seus vários usos, não em uma definição fixa, cabendo atentar para o modo como sentimentos, conhecimentos e atitudes são formados por meio de ação particulares, sem recair no pressuposto segundo o qual atos rituais caracterizam-se, essencialmente, por articular pensamentos e intencionalidades privados, inacessíveis a observadores externos (p. 77-87).

Asad lança mão do conceito de "tradição discursiva", com o objetivo de enfocar os modos pelos quais a linguagem direciona, justifica e permeia os sentidos de corpos vivos, por meio de açóes repetidas que articulam intençôes, pensamentos e sentimentos. Uma tradição é um conjunto de aspiraçóes, sensibilidades e relaçóes de sujeitos que vivem e transitam entre múltiplas temporalidades (p. 92-93). Com esse conceito, Asad não objetiva definir os significados expressos por tradiçóes islâmicas, mas atentar para os processos de disciplinamento de corpos sensíveis. (p. 93-95). Atos marcados por convençóes, fórmulas, repetiçóes e formalizaçóes (como a recitação do Corão) apontam, não tanto para o caráter rígido e coercitivo dos rituais, mas antes para tentativas de agentes de formar, e articular pensamentos, sensibilidades e sentimentos, por meio de açóes particulares que são concebidas como momentos importantes na formação do self (p. 77).

O terceiro ensaio, "Máscaras, Segurança e a Linguagem dos Números", trata de certos aspectos da tradução em relação ao moderno Estado-Nação. $\mathrm{Na}$ visão do autor, "o poder do Estado moderno depende do uso de uma linguagem distintiva: a linguagem dos números" (p. 99), que é crucial para a moldagem do caráter da vida moderna coletiva ( $\mathrm{p}$. 97). Inicialmente, o capítulo aborda a linguagem dos números à luz de noçốes antropológicas de pessoa, revisitando o famoso ensaio de Mauss (2003). Para Asad, é valiosa a sugestão deste autor de que a ideia cristã de pessoa subjaz à categoria secular de self no mundo ocidental contemporâneo, embora a noção romana de máscara seja, do seu ponto de vista, muito mais importante para a vida e a política modernas do que normalmente se assume. A noção de máscara é parte da genealogia da pessoa, comportando dualidades - como interno e externo, mente e corpo, o individual e o relacional, o privado e o público - centrais para a filosofia moderna e para as teorizações de antropólogos sobre o ritual, a cultura e as práticas de tradução em geral. As constantes indagaçôes formuladas, no ocidente, a respeito da autenticidade e autonomia dos indivíduos, das condiçôes e obstáculos para o cultivo 
da espontaneidade, e das tensas relaçôes entre o self privado e as máscaras assumidas em público, atestam a força dessas dualidades (p. 98-113).

Mas, de que modo a noção de máscara oferece pistas para pensar as relaçóes entre o Estado moderno e seus cidadãos? Máscaras não são meros instrumentos utilizados por indivíduos para controlar as impressóes sobre si mesmos, na interação com outros. Máscaras escondem segredos e oferecem sinais potencialmente enganadores (p. 104-106). Estados empregam linguagens morais para proteger suas posiçóes - enquanto representante legítimo de valores nacionais, por exemplo -, de modo a localizar potenciais inimigos dentro e fora de suas fronteiras, lançando mão de técnicas de vigilância para rastrear sinais de ameaças emanadas de cidadãos comuns (p. 116-117). Contemporaneamente, o Estado traça perfis de potenciais traidores, criminosos e terroristas, por meio de técnicas computacionais. Assim, a linguagem dos números é um instrumento da dominação moderna intimamente conectada à construção, à quantificação e à coleta de dados estatísticos sobre indivíduos potencialmente ameaçadores à ordem e aos valores liberais (p. 121-122).

Para Asad, nas últimas décadas as técnicas de investigação do Estado ganharam novos contornos, pois a construção de perfis de indivíduos singulares não se origina meramente de categorias a priori (como pertencimento étnico e religioso), mas da coleção de inúmeros dados, por meio de técnicas computacionais e complexas tecnologias de controle e vigilância, sobre características pessoais (comportamentos, crenças, padróes de consumo, gostos, etc.) que identificam esses indivíduos, tornando-os alvos do Estado, e também de corporações capitalistas. Em suma, a linguagem de números busca traduzir em possibilidades a contingência e a suspeita, de modo que as reais intençôes dos cidadáos possam ser quantificadas e, portanto, manipuladas por práticas atuariais (p. 122-125). A vultosa utilização de estatísticas expressa a necessidade crescente de o Estado superar incertezas, por meio da tentativa de ler e lidar com intençóes ocultas de um amplo número de sujeitos (p. 131). Não se trata, portanto, de averiguar se estatísticas representam fielmente, ou não, a realidade social; a linguagem matemática refaz essa realidade (p. 133).
Em um comentário escrito há alguns anos, David Scott e Charles Hirschkind (2006, p. 1) chamaram a atenção para a "atitude profundamente questionadora" e para a "postura cética" de Talal Asad, quanto às reivindicaçôes de verdade de saberes disciplinares hegemônicos. Com efeito, em Secular Translations, tal ceticismo se dirige às descrições rígidas da secularidade e do cristianismo. Assim, "a própria disputa sobre se há ou não há uma continuidade entre religiấo e o secular depende dos conceitos construídos de ambos" (p. 147); isto é, de suas histórias particulares. Termos, como religião, política, secularismo e modernidade, bem como os vocabulários associados, são entrelaçados com modos de vida:

"É a atenção ao caráter particular desse entrelaçamento que deve ser nossa principal preocupação na tentativa de entender o que as pessoas esperam, demandam ou questionam sobre 'o secular' e 'o religioso' - e por que eles assim o fazem. Os termos 'secularidade' e 'religiáo' pertencem a aquilo que Wittgenstein chamou de jogos de linguagem, jogos dentro dos quais consensos e disputas ocorrem como parte da vida ordinária jogos que são sempre capazes de ser mudados, com ou sem acordo" (p. 147-148).

A razão secular não é, evidentemente, homogênea, nem sistematiza toda a vida contemporânea (p. 150). Entretanto, as heranças de sua linguagem constituem repertórios para a análise dos dilemas e problemas da contemporaneidade. No epílogo dessa obra, gestada após quase 70 anos de carreira acadêmica, Asad se pergunta: Como deveria parecer a linguagem adequada para nosso tempo? "Eu não sei", responde, "mas não seria a linguagem do estado ou do capitalismo" (p. 158). Secular Translations é repleto de referências a Ludwig Wittgenstein, cujas investigaçôes exercem um efeito notável na obra de Asad, inclusive em suas reflexóes sobre a linguagem. De fato, como notou Das (1998, p. 170-171), para Wittgenstein os problemas filosóficos se originam no sentimento de estar perdido e em um lugar não-familiar. Respostas filosóficas são, em sua natureza, um meio de achar um cami- 
nho de volta. A antropologia pode se beneficiar dessa forma de filosofar, introduzindo hesitações no modo pelo qual nós usualmente habitamos nossos conceitos. Efetivamente, Asad nos instiga a olhar para além das limitaçóes que o comportamento e o pensamento impóem, de modo a nos pensarmos para fora de nossas linguagens presentes (Asad, 2018, p. 159), as quais podem ser repletas de falhas para lidar com os velhos e os novos problemas gerados pela vida moderna.

\section{Notas}

1 Gramática, no sentido conferido por Ludwig Wittgenstein. $\mathrm{O}$ conceito não se refere simplesmente às regras formais de construçóes sintáticas, mas ao sistema de usos que permitem que certas afirmaçôes façam sentido no interior de modos de vida particulares ( $p$. 175 , nota 18$)$.

2 Note-se de passagem que Habermas (2008) busca explorar como seria possível conciliar princípios seculares com valores relativos à cidadania e à diferença cultural. Asad, por sua vez, está mais interessado nos efeitos do poder estatal, que operam, inclusive, por meio de discursos, nos quais valores, como a igualdade e o direito à diferença, são centrais.

\section{BIBLIOGRAFIA}

ASAD, Talal. (2003), “The construction of religion as an anthropological category", in T. Asad. Formations of the secular. Christianity, Islam, modernity, Stanford, Stanford University Press, p. 27-53.

ASAD, Talal. (1993), in T. Asad, Genealogies of religion. Disciplines and reasons of power in Christianity and Islam, Baltimore, John Hopkins University Press.

DAS, Veena. (1998), "Wittgenstein and anthropology", in Annual Review of Anthropology 27:171-195.
HABERMAS, Jürgen. (2008), "Notes on post-secular society", in New Perspectives Quarterly 25(4):17-29.

MAUSS, Marcel (2003 [1938]), "Uma categoria do espírito humano: a noção de pessoa, a de 'eu'", in M. Mauss, Sociologia e Antropologia, São Paulo, Cosac e Naify, p. 367-398.

SCOTT, David \& HIRSCHKIND, Charles. (2006), "The anthropological scepticism of Talal Asad", in D. Scott \& C. Hirschkind (ed.), Powers of the secular modern. Talal Asad and his interlocutors, Stanford, Stanford University Press, p. 1-11. 